\title{
Meta-analysis of the effect of cemented and uncemented hemiarthroplasty on displaced femoral neck fracture in the elderly
}

\author{
XIANGAN KONG \\ Department of Orthopaedics, The Second People's Hospital of Hefei, Hefei, Anhui 230011, P.R. China
}

Received December 5, 2019; Accepted April 16, 2020

DOI: $10.3892 / \mathrm{etm} .2020 .8921$

\begin{abstract}
The present meta-analysis was designed to systematically evaluate the effect of cemented and uncemented hemiarthroplasty on femoral neck fractures in the elderly and its effect on intraoperative bleeding and postoperative complications. Pubmed, Embase, the Cochrane Library, CNKI and WANFANG databases were retrieved and retrieval time was from inception to February 2019. Operative time, intraoperative blood loss, length of hospital stay, postoperative complications and postoperative mortality were compared between cemented and uncemented hemiarthroplasty. RevMan 5.3 statistical software was used for analysis. A total of 16 randomized controlled trials were included, with a total of 2,384 patients undergoing hemiarthroplasty. The cemented group had a longer operation time [weighted mean difference $(\mathrm{WMD})=7.07,95 \%$ confidence interval $(\mathrm{CI})=3.91-10.23$, $\mathrm{P}<0.0001]$, but it had lower incidence of intraoperative and postoperative fracture around the prosthesis $(\mathrm{OR}=0.25$, 95\% $\mathrm{CI}=0.13-0.47, \mathrm{P}<0.0001)$ and shorter length of hospital stay $(\mathrm{WMD}=-1.78,95 \% \mathrm{CI}=-13.38--0.17, \mathrm{P}=0.03)$. There was no significant difference in pulmonary embolism, mortality, lower extremity deep vein thrombosis rate, joint dislocation rate, intraoperative blood loss and postoperative incidence of lung, urinary system and incision infection between the two groups. To summarize, compared with the uncemented group, the cemented group had long operation time and a high incidence of pulmonary embolism, but had an advantage in reducing the risk of periprosthetic fractures. In addition, cemented hemiarthroplasty did not increase the mortality rate, the rate of deep vein thrombosis in lower extremities, the rate of joint dislocation, intraoperative blood loss, and the incidence of postoperative pulmonary, urinary, and incision infections.
\end{abstract}

Correspondence to: Dr Xiangan Kong, Department of Orthopaedics, The Second People's Hospital of Hefei, 246 Heping Road, Hefei, Anhui 230011, P.R. China

E-mail: kongxiangan2007@126.com

Key words: cemented, uncemented, hemiarthroplasty, femoral neck fractures, meta-analysis

\section{Introduction}

Hip fracture, especially femoral neck fractures, is common in elderly patients caused by osteoporosis and trauma (1). Due to anatomical reasons, the femoral head is prone to a lack of blood supply after fracture, resulting in osteonecrosis and bone nonunion (2). Senile femoral neck fractures are mainly caused by osteoporosis and the incidence of femoral neck fracture is higher in women than that in men (3). The occurrence of femoral neck fracture is usually caused by a combination of many factors. The femoral neck is on the border between the osteoporosis bone and compact bone where the structure is fragile. In addition, the elderly tend to have various defects in the body, such as calcium phosphate imbalance and osteoporosis. Therefore, the elderly are prone to fracture when exposed to mild external direct or indirect violence, and osteoporosis is the most significant factor (4).

Hemiarthroplasty is a routine treatment in Garden III and Garden IV femoral neck fracture. However, a number of scholars believe that, although the incidence of complications of cemented hemiarthroplasty is low, it may result in cardiovascular and cerebrovascular complications (5). Various experts believe that uncemented hemiarthroplasty has certain advantages in regards to operation time and intraoperative blood loss (6). Therefore, the use of bone cement or uncemented hemiarthroplasty fixation is still controversial. This meta-analysis was designed to collect and analyze randomized controlled trials (RCTs) to compare the differences between the two fixation methods in regards to the operation time, intraoperative blood loss, length of hospital stay, postoperative complications and postoperative mortality in the treatment of elderly femoral neck fractures, so as to provide references for the selection of clinical prosthesis implantation.

\section{Patients and methods}

Search strategy. Two reviewers searched databases independently including Pubmed (https://www.ncbi.nlm.nih.gov/ pubmed/), Embase (https://www.embase.com/), Cochrane Library (https://www.cochranelibrary.com/), CNKI (https:// www.cnki.net/) and WANFANG (http://www.wanfangdata. com.cn/index.html) databases. The search terms included 'Hip fractures', 'Femoral fractures, 'Femoral neck fractures', 'Hemiarthroplasty', 'Artificial Femoral head replacement', 'Cemented or Cement', 'Uncementor without bone cement', 
'Noncemented or uncemented' and 'Biotype or cementless'. The retrieval time was from inception to February, 2019.

Inclusion and exclusion criteria. Inclusion criteria included: i) subjects aged 60 years or older with femoral neck fractures; ii) the intervention measures were cemented or uncemented hemiarthroplasty; iii) the study type was clinical prospective RCT.

Exclusion criteria included: i) low quality or non-RCT; ii) studies that failed to obtain original texts or accurately extract data; iii) subject age $<60$ years; iv) repeated literature; v) patients undergoing secondary surgery for the same disease.

Data extraction and quality assessment. Two reviewers independently screened the literature and extracted data. Concerning controversial literature, a third reviewer decided whether to include a study or not. The data extracted included baseline data and outcome indicators.

The modified Jadad scale (7) was used to evaluate the quality of the included studies. Blinding, randomization, concealment allocation and withdrawal in the study were analyzed respectively. The total score is 7 . Studies with scores more than or equal to 4 are considered high-quality, and those with scores less than 4 are considered low-quality. Extremely low-quality studies were excluded to ensure the reliability of the meta-analysis results.

Outcome indicators. All the outcome indicators are as follows (and indicated in Table I with small letters): a) periprosthetic fractures; b) postoperative joint dislocation; c) time of operation; d) incision infection; e) intraoperative blood loss; f) length of hospital stay; g) postoperative cerebrovascular accident; h) postoperative myocardial infarction; i) postoperative pulmonary infection; j) pulmonary embolism; k) postoperative urinary tract infection; l) postoperative deep vein thrombosis; $\mathrm{m}$ ) mortality within six months after surgery; n) mortality within one year after surgery.

Statistical analysis. Meta-analysis of the extracted data was performed using the RevMan 5.3 software (https://training.cochrane.org/online-learning/ core-software-cochrane-reviews/revman) recommended by the Cochrane collaboration (London, UK). We calculated the odds ratio (OR) and $95 \%$ confidence interval (CI) for the count data, and calculated the weighted mean difference (WMD) and $95 \% \mathrm{CI}$ for the measurement data. $\mathrm{I}^{2}$ was used to test for heterogeneity. $\mathrm{P}<0.05$ and $\mathrm{I}^{2}>50 \%$ indicated the heterogeneity of each study. We analyzed the cause of the heterogeneity and used the random effect model for analysis. If $\mathrm{P}>0.05$ and $\mathrm{I}^{2}<50 \%$, the heterogeneity of a study was low and we used the fixed-effect model for analysis. Funnel plots were used to analyze publication bias of the included studies. Studies with significant publication bias were excluded.

\section{Results}

Study selection and study characteristics. We initially searched 422 articles and finally included 16 studies (8-23), including 1,194 cases in the cemented group and 1,190 cases in the uncemented group. The literature screening process is shown in Fig. 1. Baseline information of the included studies is documented in Table I.

\section{Results of the meta-analysis}

Periprosthetic fractures. A total of 8 studies $(8,11-14,16,21,23)$ reported periprosthetic fractures and 997 cases were included in the analysis. There was no significant heterogeneity in the results of the studies $\left(\mathrm{P}=0.31, \mathrm{I}^{2}=16 \%\right)$. The fixed-effect model was used for analysis and the results showed that the incidence of periprosthetic fractures in the cemented group was lower than that in the uncemented group (OR $=0.25$, 95\% CI=0.13-0.47, P<0.0001; Fig. 2).

Postoperative joint dislocation. A total of 8 studies in the literature $(8,11,12,14,16,17,21,23)$ reported postoperative joint dislocation and 1,320 cases were included in the analysis. There was no significant heterogeneity in the results of various studies $\left(\mathrm{P}=0.72, \mathrm{I}^{2}=0 \%\right)$. The fixed-effect model was used for analysis and the results showed that there was no significant difference between the two groups in the incidence of joint dislocation after surgery $(\mathrm{OR}=1.80,95 \% \mathrm{CI}=0.85-3.80, \mathrm{P}<0.12$; Fig. 3).

Time of operation. A total of 10 studies $(8,10,11,13,15,17,18,20$, $21,23)$ reported time of operation and 1,691 cases were included in the analysis. There was significant heterogeneity in the results of the studies $\left(\mathrm{P}<0.00001, \mathrm{I}^{2}=77 \%\right)$. The random effect model was used for analysis and the results showed that the time of operation in the cemented group was longer than that in the uncemented group (WMD $=7.07,95 \% \mathrm{CI}=3.91-10.23$, $\mathrm{P}<0.0001$; Fig. 4).

Incision infection. A total of 10 studies $(8,10-12,14,16-18,21,23)$ reported incision infection and 1,453 cases were included in the analysis. There was no significant heterogeneity in the results of the studies $\left(\mathrm{P}<0.88, \mathrm{I}^{2}=0 \%\right)$. The fixed-effect model was used for analysis and the results showed that here was no significant difference between the two groups in the incidence of incision infection (OR=1.11, 95\% CI=0.69-1.79, $\mathrm{P}=0.66$; Fig. 5).

Intraoperative blood loss. A total of 12 studies (8-13,15,16,18, $20,21,23$ ) reported intraoperative blood loss and 1,761 cases were included in the analysis. There was significant heterogeneity in the results of the studies $\left(\mathrm{P}<0.00001, \mathrm{I}^{2}=85 \%\right)$. The random effect model was used for analysis and the results showed that there was no significant difference between the two groups in the intraoperative blood loss (WMD $=15.14$, 95\% CI=-10.31-40.60, P=0.24; Fig. 6).

Length of hospital stay. A total of 6 studies $(8,13,15,17,21,22)$ reported the length of hospital stay and 968 cases were included in the analysis. There was significant heterogeneity in the results of the studies $\left(\mathrm{P}<0.00001, \mathrm{I}^{2}=84 \%\right)$. The random effect model was used for analysis and the results showed that the length of hospital stay in the cemented group was less than that in the uncemented group (WMD $=-1.78,95 \% \mathrm{CI}=-13.38--0.17$, $\mathrm{P}=0.03$ ) (Fig. 7).

Postoperative cerebrovascular accident. A total of 5 studies $(13,14,16,17,21)$ reported postoperative cerebrovascular 
Table I. Baseline characteristics of the included studies.

\begin{tabular}{|c|c|c|c|c|c|}
\hline $\begin{array}{l}\text { Studies } \\
\text { First author, year (Ref.) }\end{array}$ & Country & $\begin{array}{c}\text { No. of patients } \\
\text { (cemented/uncemented) }\end{array}$ & $\begin{array}{c}\text { Mean age } \\
\text { (cemented/uncemented) } \\
\text { (years) }\end{array}$ & $\begin{array}{l}\text { Follow-up } \\
\text { time (months) }\end{array}$ & Outcomes \\
\hline Deangelis, 2012 (9) & USA & $66 / 64$ & $81.8 / 82.8$ & 12 & $\mathrm{e}, \mathrm{m}, \mathrm{n}$ \\
\hline Du, 2014 (23) & China & $47 / 47$ & $74.5 / 74.2$ & 12 & $\mathrm{a}, \mathrm{b}, \mathrm{c}, \mathrm{d}, \mathrm{e}, \mathrm{i}, \mathrm{k}$ \\
\hline Emery, 1991 (10) & UK & $27 / 26$ & $80 / 81$ & 17 & $\mathrm{c}, \mathrm{d}, \mathrm{j}, 1, \mathrm{n}$ \\
\hline Figved, 2009 (11) & Norway & $112 / 108$ & $83.4 / 83.0$ & 12 & $\mathrm{a}, \mathrm{b}, \mathrm{c}, \mathrm{d}, \mathrm{e}, \mathrm{h}, \mathrm{i}, \mathrm{j}, \mathrm{m}, \mathrm{n}$ \\
\hline Inngul, 2015 (12) & Sweden & $67 / 74$ & $81.2 / 81.3$ & 12 & $\mathrm{a}, \mathrm{b}, \mathrm{d}, \mathrm{e}, \mathrm{h}, \mathrm{i}, \mathrm{k}, \mathrm{m}, \mathrm{n}$ \\
\hline Khorami, 2016 (14) & Iran & $22 / 29$ & $79 / 71.7$ & 6 & $\mathrm{a}, \mathrm{b}, \mathrm{d}, \mathrm{g}, \mathrm{k}$ \\
\hline Langslet, 2014 (15) & Norway & $111 / 108$ & $83.4 / 83.0$ & 12 & $\mathrm{c}, \mathrm{e}, \mathrm{f}, \mathrm{m}, \mathrm{n}$ \\
\hline $\mathrm{Li}, 2017$ (13) & China & $35 / 35$ & $76.4 / 77.2$ & 6 & a,c,e,f,g,l \\
\hline Мa, 2016 (8) & China & $30 / 30$ & $66.2 / 68.7$ & 12 & $\mathrm{a}, \mathrm{b}, \mathrm{c}, \mathrm{d}, \mathrm{e}, \mathrm{f}, \mathrm{l}$ \\
\hline Moerman, 2017 (16) & Netherland & $110 / 91$ & $84 / 84$ & 12 & $\mathrm{a}, \mathrm{b}, \mathrm{d}, \mathrm{e}, \mathrm{g}, \mathrm{h}, \mathrm{i}, \mathrm{j}, \mathrm{k}, \mathrm{l}, \mathrm{n}$ \\
\hline Pan, 2013 (18) & China & $38 / 35$ & $70.5 / 72.2$ & - & $\mathrm{c}, \mathrm{d}, \mathrm{e}, \mathrm{i}, \mathrm{l}$ \\
\hline Parker, 2010 (17) & England & $200 / 200$ & $83 / 83$ & 24 & $\mathrm{~b}, \mathrm{c}, \mathrm{d}, \mathrm{f}, \mathrm{g}, \mathrm{h}, \mathrm{j}, \mathrm{l}, \mathrm{n}$ \\
\hline Sonne-Holm, 1983 (19) & Denmark & $55 / 57$ & $82.1 / 82.2$ & 12 & $\mathrm{~m}, \mathrm{n}$ \\
\hline Talsnes, 2013 (20) & Norway & $162 / 172$ & $84.3 / 84.0$ & 12 & $\mathrm{c}, \mathrm{e}, \mathrm{n}$ \\
\hline Taylor, 2012 (21) & New Zealand & $80 / 80$ & $85.3 / 85.1$ & 24 & $\mathrm{a}, \mathrm{b}, \mathrm{c}, \mathrm{d}, \mathrm{e}, \mathrm{f}, \mathrm{g}, \mathrm{k}, \mathrm{m}$ \\
\hline Vidović, 2015 (22) & Croatia & $30 / 30$ & - & 12 & $\mathrm{f}, \mathrm{n}$ \\
\hline
\end{tabular}

a, Periprosthetic fractures; b, postoperative joint dislocation; c, time of operation; d, incision infection; e, intraoperative blood loss; $\mathrm{f}$, length of hospital stay; $\mathrm{g}$, postoperative cerebrovascular accident; $\mathrm{h}$, postoperative myocardial infarction; i, postoperative pulmonary infection; $\mathrm{j}$, pulmonary embolism; $\mathrm{k}$, postoperative urinary tract infection; 1, postoperative deep vein thrombosis; $\mathrm{m}$, mortality within six months after surgery; $\mathrm{n}$, mortality within one year after surgery.

\section{Potentially relevant references identified initially: 422}

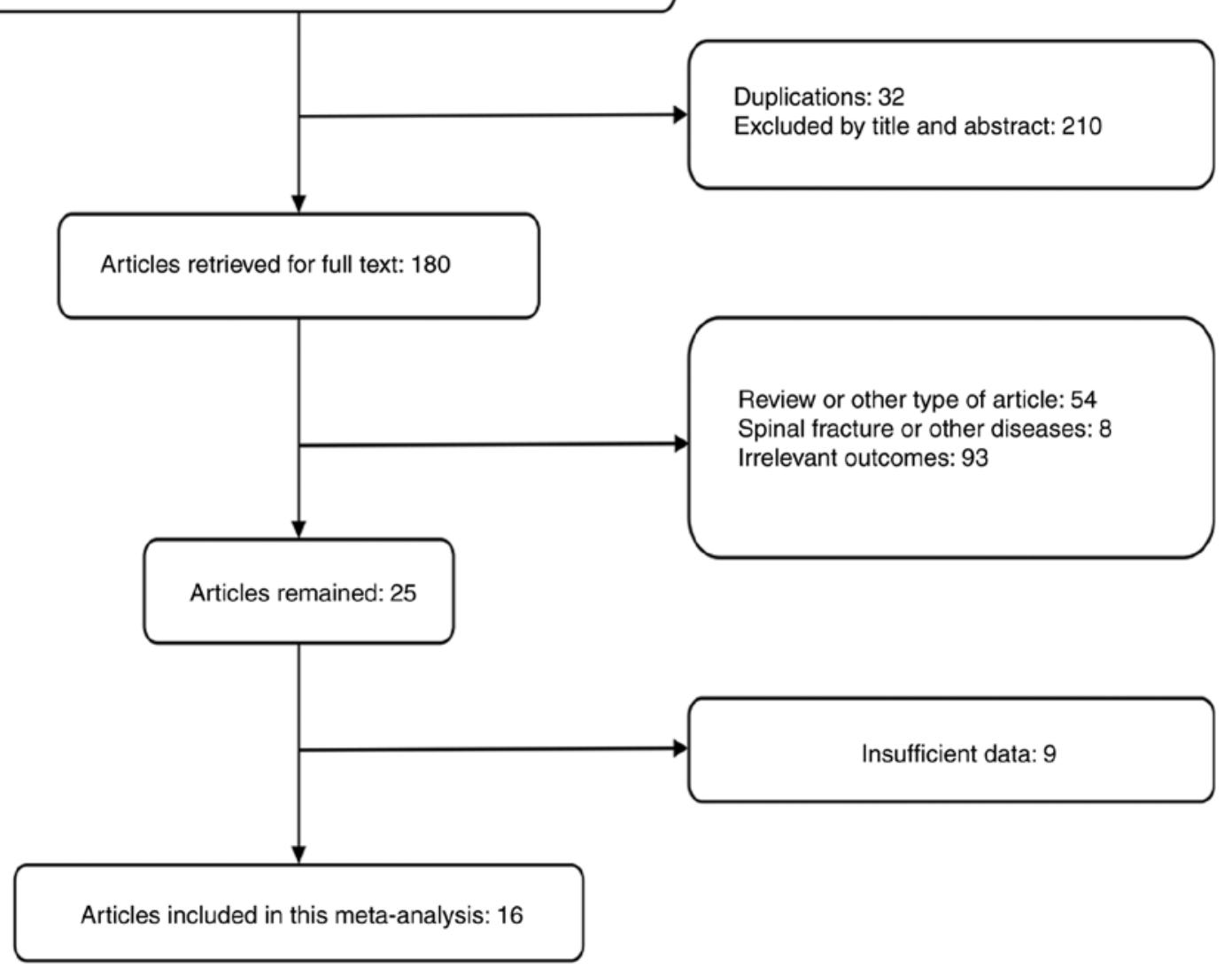

Figure 1. Study flow and selection diagram. 


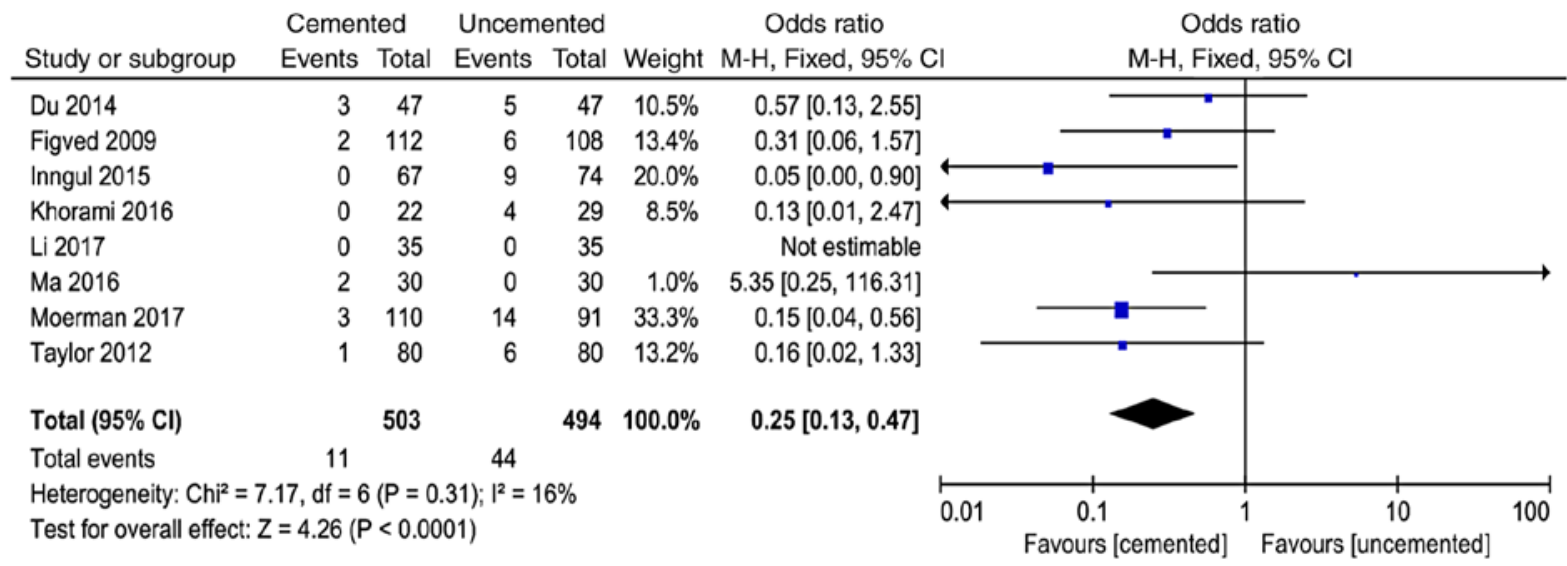

Figure 2. Forest plot for comparison of periprosthetic fractures between the uncemented and cemented groups.

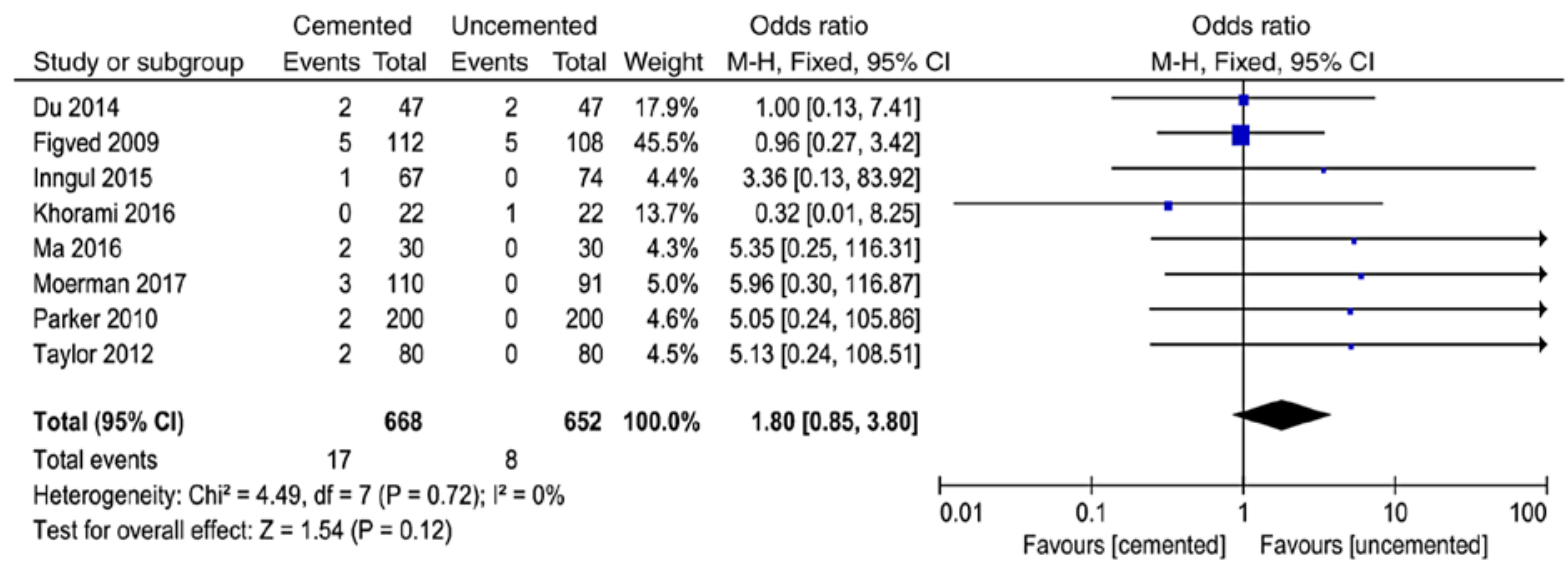

Figure 3. Forest plot for comparison of postoperative joint dislocation between the uncemented and cemented groups.

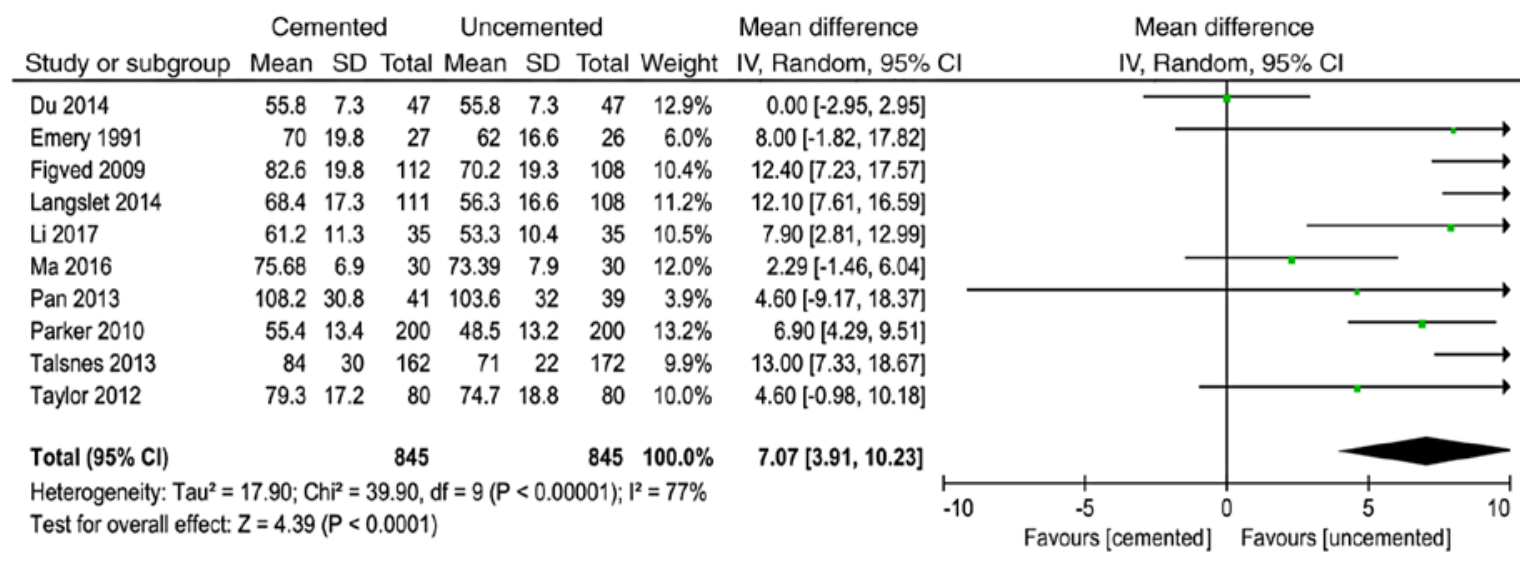

Figure 4. Forest plot for comparison of time of operation between the uncemented and cemented groups.

accident and 882 cases were included in the analysis. There was no significant heterogeneity in the results of the studies $\left(\mathrm{P}=0.63, \mathrm{I}^{2}=0 \%\right)$. The fixed-effect model was used for analysis and the results showed that there was no significant difference between the two groups in the postoperative cerebrovascular accident ( $\mathrm{OR}=1.57,95 \% \mathrm{CI}=0.72-3.39, \mathrm{P}=0.25$; Fig. 8 ).

Postoperative myocardial infarction. A total of 4 studies (11, $12,16,17)$ reported postoperative myocardial infarction and
962 cases were included in the analysis. There was no significant heterogeneity in the results of the studies $\left(\mathrm{P}=0.74, \mathrm{I}^{2}=0 \%\right)$. The fixed-effect model was used for analysis and the results showed that there was no significant difference between the two groups in the postoperative myocardial infarction $(\mathrm{OR}=0.60,95 \% \mathrm{CI}=0.20-1.75, \mathrm{P}=0.35$; Fig. 9).

Postoperative pulmonary infection. A total of 5 studies $(11,12,16,18,23)$ reported postoperative pulmonary 
Cemented Uncemented Odds ratio

Odds ratio

Study or subgroup Events Total Events Total Weight M-H, Fixed, $95 \% \mathrm{Cl}$

$\mathrm{M}-\mathrm{H}$, Fixed, $95 \% \mathrm{Cl}$

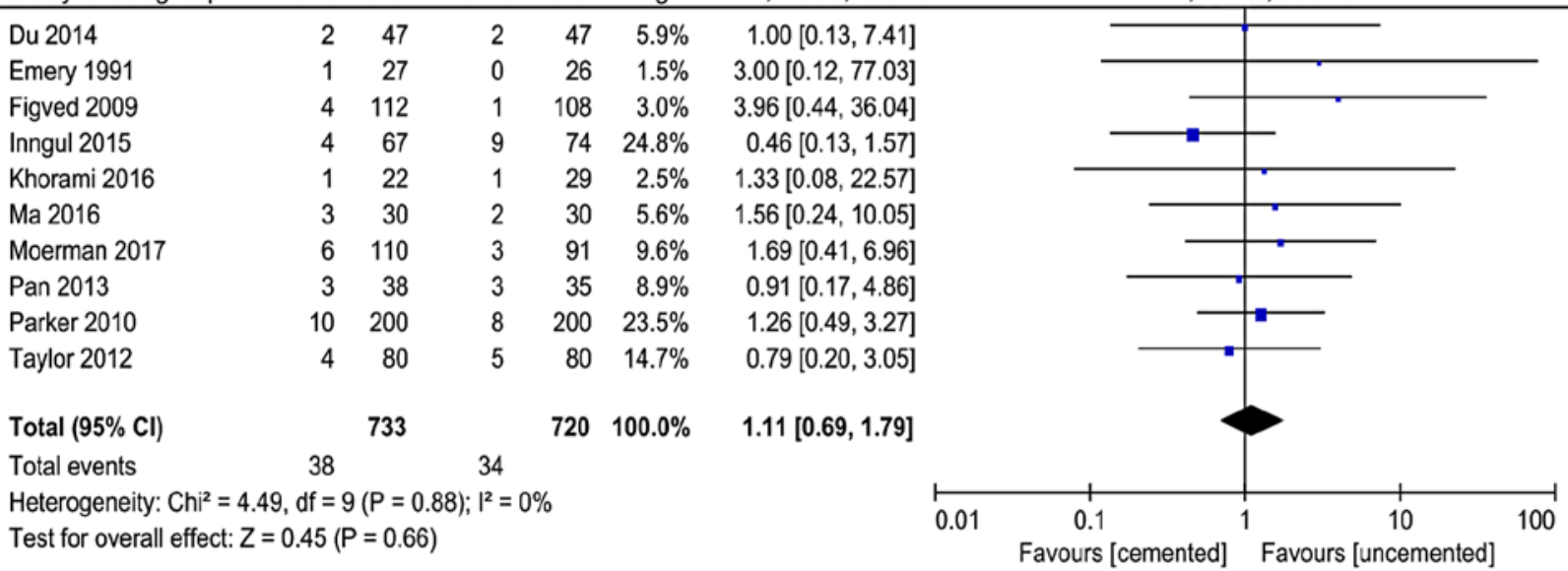

Figure 5. Forest plot for comparison of incision infection between the uncemented and cemented groups.

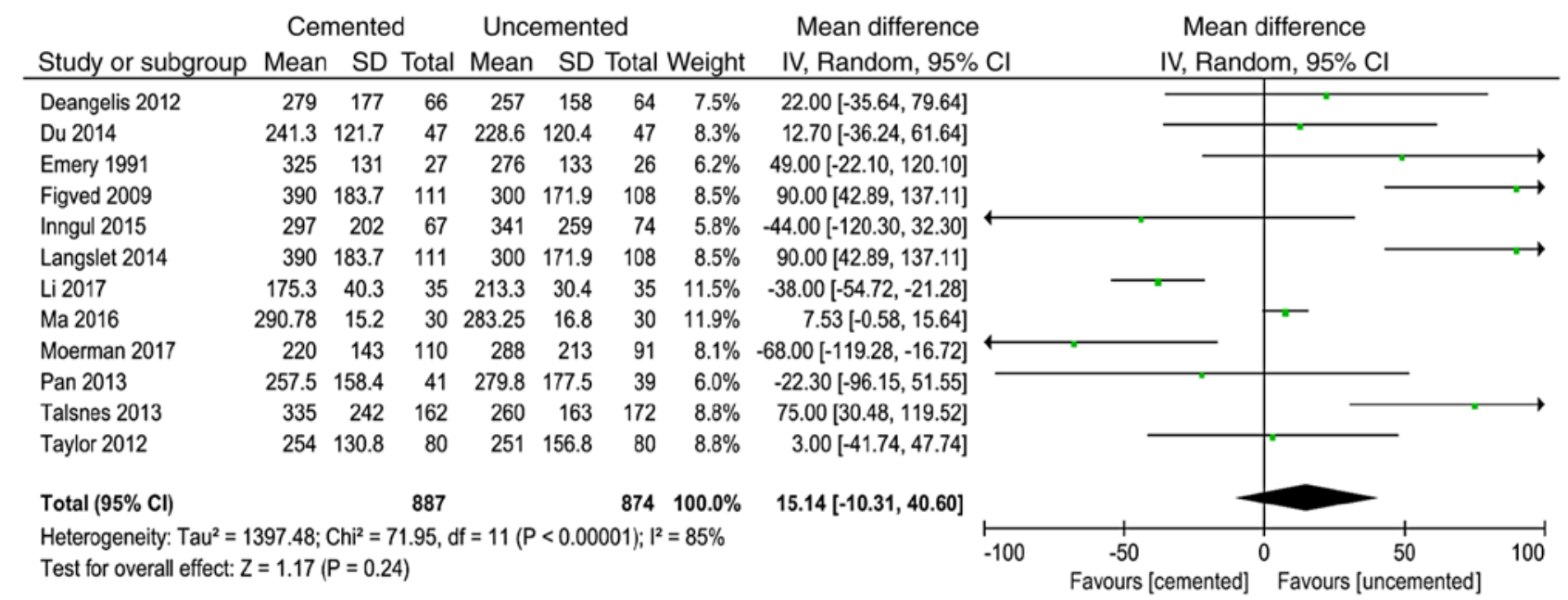

Figure 6. Forest plot for comparison of intraoperative blood loss between the uncemented and cemented groups.

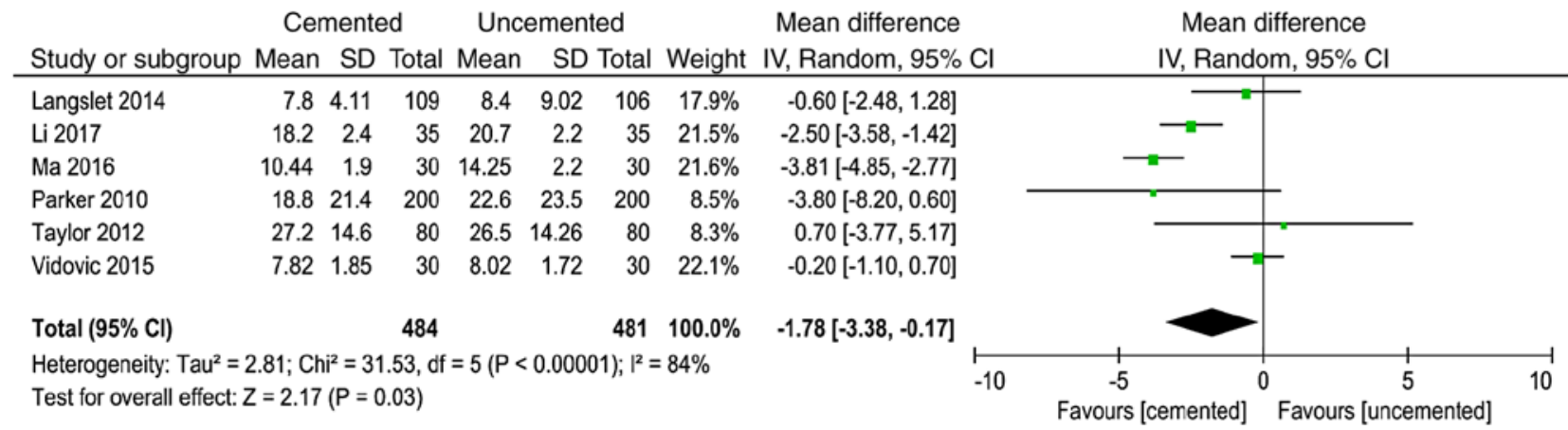

Figure 7. Forest plot for comparison of length of hospital stay after TIMI between the uncemented and cemented groups.

infection and 729 cases were included in the analysis. There was no significant heterogeneity in the results of the studies $\left(\mathrm{P}=0.74, \mathrm{I}^{2}=0 \%\right)$. The fixed-effect model was used for analysis and the results showed that there was no significant difference between the two groups in the postoperative pulmonary infection $(\mathrm{OR}=0.76,95 \% \mathrm{CI}=0.41-1.41, \mathrm{P}=0.38$; Fig. 10).
Pulmonary embolism. A total of 4 studies $(10,11,16,17)$ reported pulmonary embolism and 874 cases were included in the analysis. There was no significant heterogeneity in the results of the studies $\left(\mathrm{P}=0.83, \mathrm{I}^{2}=0 \%\right)$. The fixed-effect model was used for analysis and the results showed that there was no significant difference between the two groups in the pulmonary embolism (OR=3.95, 95\% CI=0.97-16.02, $\mathrm{P}=0.05$; Fig. 11). 
Cemented Uncemented

Odds ratio

Odds ratio

Study or subgroup Events Total Events Total Weight $\mathrm{M}-\mathrm{H}$, Fixed, 95\% $\mathrm{Cl}$

$\mathrm{M}-\mathrm{H}$, Fixed, $95 \% \mathrm{Cl}$

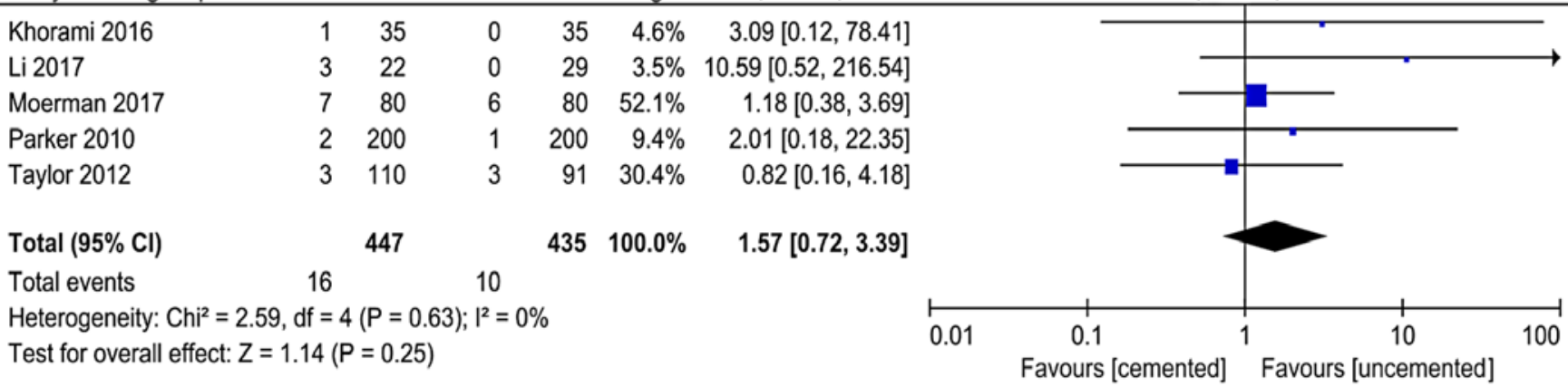

Figure 8. Forest plot for comparison of postoperative cerebrovascular accident between the uncemented and cemented groups.

Cemented Uncemented Odds ratio

Odds ratio

Study or subgroup Events Total Events Total Weight M-H, Fixed, 95\% Cl

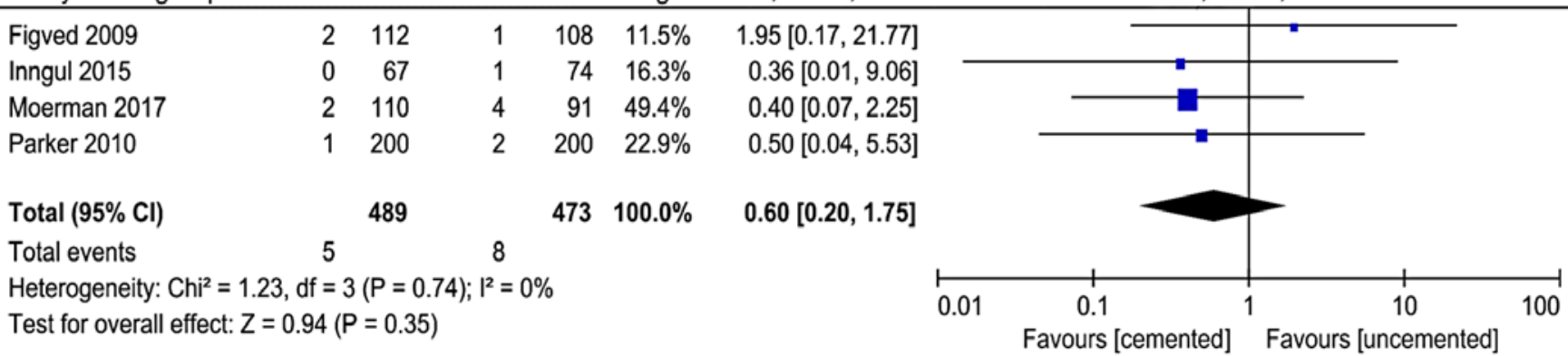

Figure 9. Forest plot for comparison of postoperative myocardial infarction between the uncemented and cemented groups.

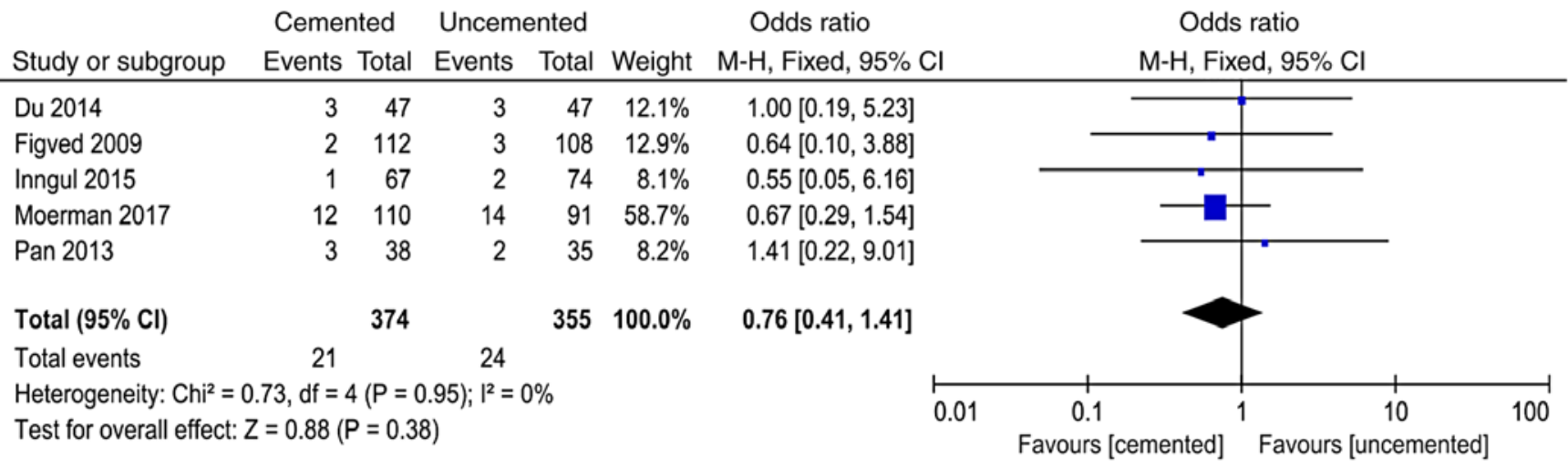

Figure 10. Forest plot for comparison of postoperative pulmonary infection between the uncemented and cemented groups.

Cemented Uncemented Odds ratio Odds ratio

Study or subgroup Events Total Events Total Weight $\mathrm{M}-\mathrm{H}$, Fixed, 95\% Cl

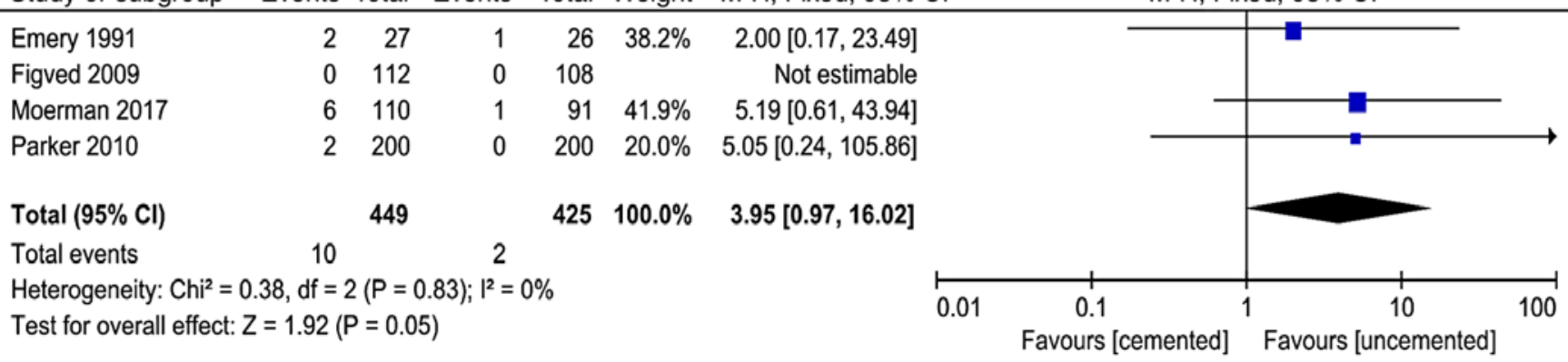

Figure 11. Forest plot for comparison of pulmonary embolism between the uncemented and cemented groups. 


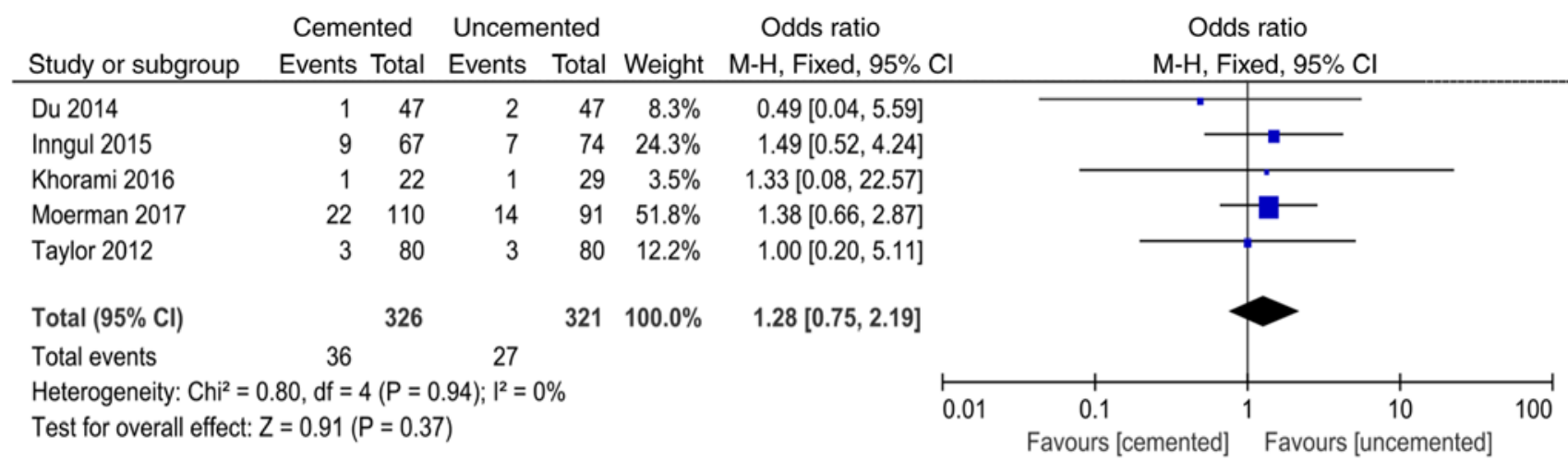

Figure 12. Forest plot for comparison of postoperative urinary tract infection between the uncemented and cemented groups.

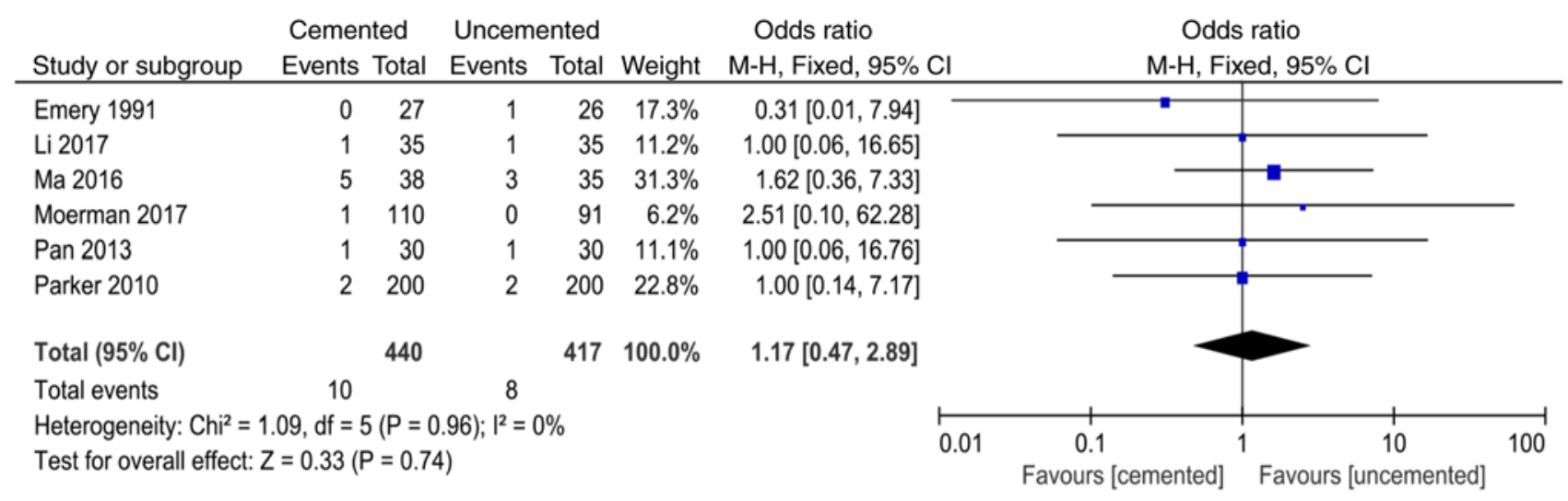

Figure 13. Forest plot for comparison of postoperative deep vein thrombosis between the uncemented and cemented groups.

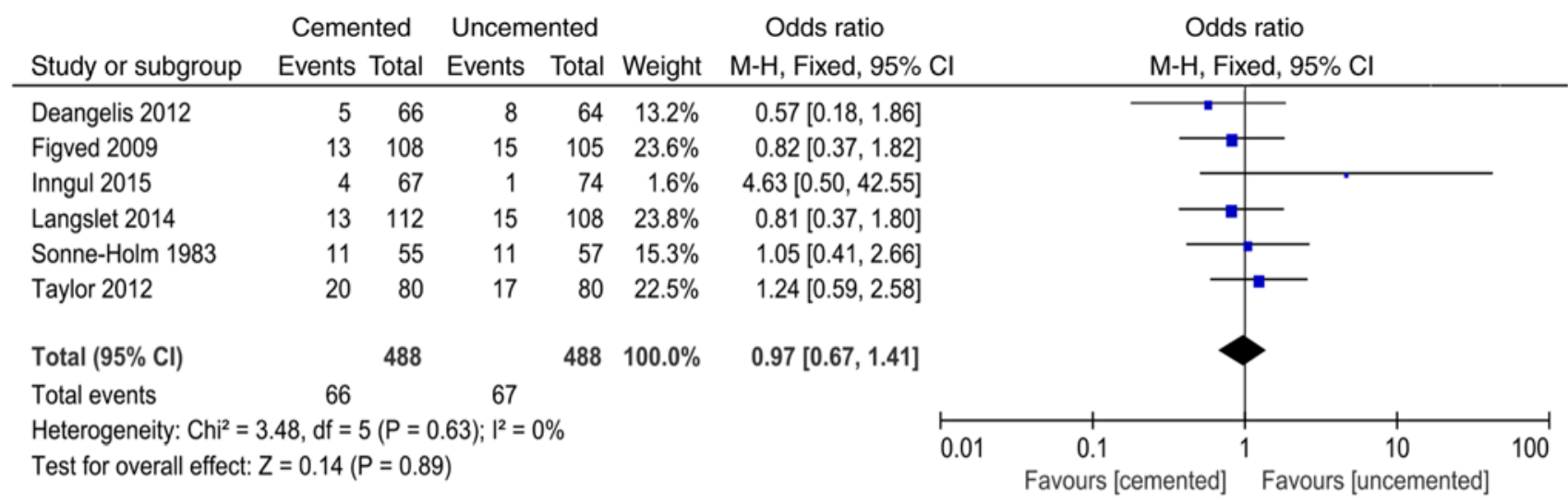

Figure 14. Forest plot for comparison of mortality within six months after surgery between the uncemented and cemented groups.

Postoperative urinary tract infection. A total of 5 studies (12, $14,16,21,23)$ reported postoperative urinary tract infection and 647 cases were included in the analysis. There was no significant heterogeneity in the results of the studies $(\mathrm{P}=0.94$, $\mathrm{I}^{2}=0 \%$ ). The fixed-effect model was used for analysis and the results showed that there was no significant difference between the two groups in the postoperative urinary tract infection $(\mathrm{OR}=1.28,95 \% \mathrm{CI}=0.75-2.19, \mathrm{P}=0.37$; Fig. 12).

Postoperative deep vein thrombosis. A total of 6 studies (8, $10,13,16-18)$ reported postoperative deep vein thrombosis and 857 cases were included in the analysis. There was no significant heterogeneity in the results of the studies $(\mathrm{P}=0.96$, $\mathrm{I}^{2}=0 \%$ ). The fixed-effect model was used for analysis and the results showed that there was no significant difference between the two groups in the postoperative deep vein thrombosis $(\mathrm{OR}=1.17,95 \% \mathrm{CI}=0.47-2.89, \mathrm{P}=0.74$; Fig. 13).

Mortality within six months after surgery. A total of 6 studies $(9,11,12,15,19,21)$ reported mortality within six months after surgery and 976 cases were included in the analysis. There was no significant heterogeneity in the results of the studies 


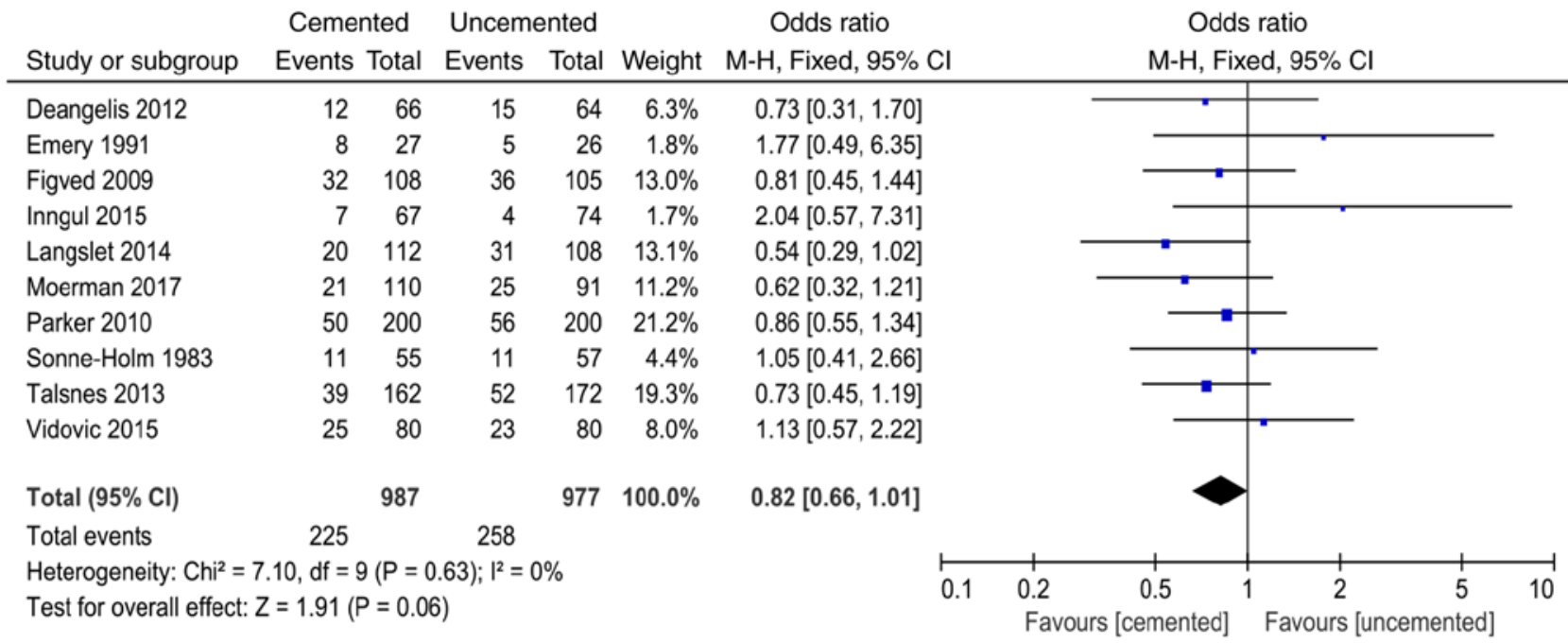

Figure 15. Forest plot for comparison of mortality within one year after surgery between the uncemented and cemented groups.
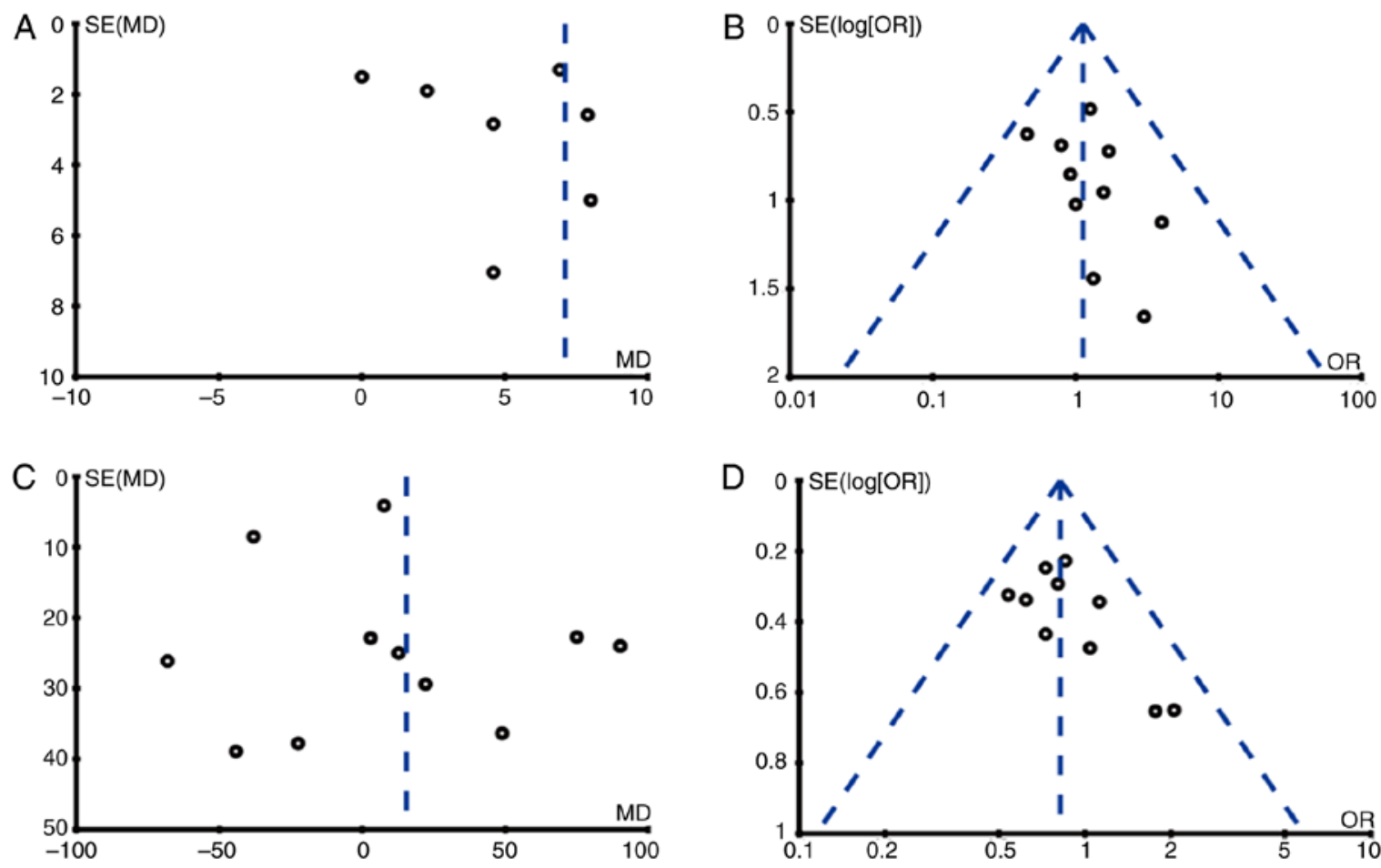

Figure 16. Funnel plots for publication bias assessment. (A) Time of operation, (B) incision infection, (C) intraoperative blood loss and (D) mortality within one year after surgery.

$\left(\mathrm{P}=0.63, \mathrm{I}^{2}=0 \%\right)$. The fixed-effect model was used for analysis and the results showed that there was no significant difference between the two groups in the mortality within six months after surgery $(\mathrm{OR}=0.97,95 \% \mathrm{CI}=0.67-1.41, \mathrm{P}=0.89$; Fig. 14).

Mortality within one year after surgery. A total of 10 studies $(9-12,15-17,19,20,22)$ reported mortality within one year after surgery and 1964 cases were included in the analysis. There was no significant heterogeneity in the results of the studies $\left(\mathrm{P}=0.63, \mathrm{I}^{2}=0 \%\right)$. The fixed-effect model was used for analysis and the results showed that there was no significant difference between the two groups in the mortality within one year after surgery $(\mathrm{OR}=0.82,95 \% \mathrm{CI}=0.66-1.01, \mathrm{P}=0.06$; Fig. 15).
Publication bias and quality assessment. We conducted publication bias analysis on outcome indicators of 10 studies by funnel plots and the results showed that there was publication bias in the result of time of operation and the other 3 funnel plots had good symmetry, indicating no obvious publication bias (Fig. 16). The quality assessment of all included studies is shown in Table II. All the results are greater than 4 points, indicating that the quality of the included studies is good.

\section{Discussion}

Hemiarthroplasty is one of the most important methods to resolve unstable femoral neck fractures in elderly patients. 
Table II. Modified Jadad scale.

\begin{tabular}{|c|c|c|c|c|c|}
\hline $\begin{array}{l}\text { Studies } \\
\text { First author, year (Ref.) }\end{array}$ & Blinding & Randomization & $\begin{array}{l}\text { Concealment } \\
\text { allocation }\end{array}$ & Withdrawal & $\begin{array}{l}\text { Total } \\
\text { scores }\end{array}$ \\
\hline Deangelis, 2012 (9) & 2 & 2 & 1 & 1 & 6 \\
\hline Du, 2014 (23) & 2 & 2 & 1 & 1 & 6 \\
\hline Emery, 1991 (10) & 2 & 2 & 1 & 1 & 6 \\
\hline Figved, 2009 (11) & 2 & 2 & 2 & 1 & 7 \\
\hline Inngul, 2015 (12) & 2 & 1 & 1 & 1 & 5 \\
\hline Khorami, 2016 (14) & 1 & 2 & 1 & 1 & 5 \\
\hline Langslet, 2014 (15) & 2 & 2 & 2 & 1 & 7 \\
\hline Li, 2017 (13) & 1 & 1 & 1 & 1 & 4 \\
\hline Ma, $2016(8)$ & 1 & 2 & 2 & 1 & 6 \\
\hline Moerman, 2017 (16) & 2 & 1 & 1 & 1 & 5 \\
\hline Pan, 2013 (18) & 2 & 2 & 1 & 1 & 6 \\
\hline Parker, 2010 (17) & 1 & 1 & 1 & 1 & 4 \\
\hline Sonne-Holm, 1983 (19) & 1 & 2 & 2 & 1 & 6 \\
\hline Talsnes, 2013 (20) & 1 & 2 & 1 & 1 & 5 \\
\hline Taylor, 2012 (21) & 2 & 2 & 1 & 1 & 6 \\
\hline Vidović, 2015 (22) & 2 & 1 & 1 & 1 & 5 \\
\hline
\end{tabular}

The modified Jadad scale (7) was used to evaluate the quality of the included studies. Blinding: A completely consistent placebo or similar approach was used ( 2 scores), blinding not specifically described ( 1 score), improper blinding ( 0 score). Randomization: A computer-generated random method or similar method ( 2 scores), a random trial but no method of random allocation (1 score), a non-random method ( 0 score). Concealment allocation: Unpredictable allocation method for clinicians and subjects ( 2 scores), random number table or other random allocation scheme (1 score), improper allocation ( 0 score). Withdrawal: The number and reasons of withdrawal and loss of follow-up are described ( 1 score), the number and reasons of withdrawal and loss of follow-up are not described ( 0 score). Studies with scores $\geq 4$ are considered high-quality, and those with scores $<4$ are considered low-quality. Extremely low-quality studies were excluded to ensure the reliability of the meta-analysis results.

Some scholars believe that the incidence of complications of cemented hemiarthroplasty is low, but it may result in cardiovascular and cerebrovascular complications (24). Some scholars believe that the uncemented prosthesis has certain advantages in operation time and intraoperative blood loss, but the pain appears earlier (25). Due to the differences among countries, regions, patients and races, as well as the differences in surgical techniques, there is no unified conclusion on these issues in clinical practice. At present, there is no unified consensus and guidelines on how to select prostheses for hemiarthroplasty. Therefore, the present meta-analysis adopted currently available data to provide a theoretical basis for the clinical treatment of femoral neck fractures.

The meta-analysis results showed that the choice of bone cement as prosthesis could reduce intraoperative and postoperative fracture around the prosthesis. The main reasons were that the cemented hemiarthroplasty stability depends on the contact scope of prosthesis and medullary cavity and close degree. Surgeons continuously tap cemented hemiarthroplasty in order to maintain the stability of the prosthesis, which could lead to femur fractures. If the prosthesis is not stable, the possibility of loosening of the prosthesis may increase during postoperative functional exercise and the loose prosthesis is unable to disperse the surrounding stress well, which may lead to fracture around the prosthesis in the process of loading on the ground. As cemented hemiarthroplasty is effectively filled with bone cement, surgeons can easily ensure the area where the prosthesis fits into the medullary cavity during the process of striking the prosthesis, thus reducing the possibility of fracture around the prosthesis. In addition, the effects of the two surgical methods on periprosthetic fractures are very different. This may be affected by some confounding factors, such as the different drugs that patients may take. Therefore, we need to take this result with caution.

Although there was no obvious difference in the result of joint dislocation between the cemented and uncemented groups, surgeons tend to only have one chance to handle cement. If the prosthesis position is poor, it is difficult to adjust the position again. However, the uncemented hemiarthroplasty is easy to pull out, thus surgeons can adjust the anteversion angle and thus avoid joint dislocation after surgery due to the unsuitable angle. There are many reasons for dislocation after hip arthroplasty, such as age, combined limb or mental disease, approach, diameter of the artificial femoral head, surgical history, placement of prosthesis and improper handling; all of which are risk factors for dislocation after hip arthroplasty. However, whether the selection of prosthesis is a risk factor requires further analysis of large sample data.

Hemiarthroplasty with bone cement shank as prosthesis was found to increase the operation time but did not increase the intraoperative blood loss and infection rate. Azegami et al (26) point out in their meta-analysis that the cemented group had more intraoperative blood loss than the uncemented group, but this study showed no significant difference between the two 
groups in intraoperative blood loss. Studies included in this study were of high quality and the number of included cases was large, thus it was more convincing. Although the bone cement groups have an increased chance of bleeding, bone cement is able to immediately close the medullary cavity, thus reducing intraoperative blood loss. The uncemented group avoids the time required to prepare and place the cement, but the closure of the medullary cavity is not immediate. The above reasons explain why the two groups have no significant difference in the intraoperative blood loss. Infection is one of the most serious complications for surgeons and an increase in operation time may increase the risk of surgical infection. However, bone cement contains antibiotics that can be released slowly, which may play an important role in the prevention of infection and thus reduce the risk of infection. The operation time of the uncemented group was short, which was significant in reducing the risk of infection, but there is no coating on uncemented hemiarthroplasty to prevent infection, which may be the reason why there was no significant difference in the postoperative infection rate between the two groups. The skill level of the surgeon and the patient's race and disease status may lead to the heterogeneity of the results. Although this analysis could not completely eliminate the heterogeneity, it still has clinical reference value because of the large number of included cases.

Hemiarthroplasty with bone cement shank as prosthesis could reduce the length of hospital stay, which is of great significance for patients and their family burden. Previous meta-analyses did not analyze the length of hospital stay of patients. In this study, the length of hospital stay was analyzed and it was found that hemiarthroplasty with bone cement shank as prosthesis could significantly reduce the length of hospital stay and thus reduce the burden on the family. Considering the reasons, cemented hemiarthroplasty could provide patients with good functional recovery in the short term. Cemented hemiarthroplasty could fill the gap between the bone marrow cavity and artificial prosthesis by bone cement. According to proper pressure, bone cement can be embedded into the gap of bone trabecula so that the interlacing between bone trabecula and bone cement could be formed, thus making the fixation of cemented hemiarthroplasty more firm. Therefore, most patients undergoing cemented hemiarthroplasty have a short time in bed after surgery and patients can get out of bed in a short period of time and recover quickly after surgery. The uncemented hemiarthroplasty has a porous structure on its surface. After implantation into the human body, it mainly relies on the growth of bone tissue to form a tight biological fixation between the bone and the prosthesis surface. The bone growth period of the biological prosthesis is relatively long and the stability of the early postoperative period is poor, thus the postoperative time in bed of the patient is relatively long.

Although the incidence of pulmonary embolism in the uncemented group was significantly lower than that in the cemented group, the incidence of postoperative pulmonary infection, urinary tract infection and lower limb deep vein thrombosis were not reduced. The incidence of pulmonary embolism is consistent with the study of Borghi et al (27). Among the 1,640 patients, the incidence of pulmonary embolism after total hip replacement with cemented hemiarthroplasty was $2.4 \%$, while the incidence of pulmonary embolism after total hip replacement with uncemented prosthesis was $0.34 \%$. In the process of prosthesis implantation, when bone cement is filled into the intramedullary cavity, intramedullary pressure increases rapidly, leading to fat, bone marrow and air entering the circulatory system and forming an embolism. Bone cement itself also acts on the calcium channel of vascular smooth muscle and then relaxes blood vessels, resulting in lower blood pressure. At the same time, the polymerization of bone cement generates heat and local high temperature could rapidly damage the vascular endothelium, further causing thrombosis (14).

There was no significant difference in mortality between the two groups for 6 months and 1 year after surgery, which corroborated the results of Azegami et al (26). Due to the general advanced age of the patients, preoperative basic diseases, such as cardiovascular and cerebrovascular diseases, hypertension, diabetes, and lung diseases may result in death. The use of bone cement may be a factor in mortality, but large sample RCTs are required for analysis.

At present, more and more types of prostheses are applied in the clinic, including biological prostheses, cemented hemiarthroplasty and various new materials. 3D printing technology is also being used in hemiarthroplasty $(5,6)$. Different prostheses have their own advantages and disadvantages. Therefore, we need to design appropriate surgical methods for different patients.

To sum up, in hemiarthroplasty, the cemented group had a long operation time and high incidence of pulmonary embolism, but had an obviously reduced incidence of intraoperative and postoperative fracture around the prosthesis and reduced length of hospital stay. There was no significant difference in incidence of death, lower extremity deep vein thrombosis, joint dislocation, intraoperative blood loss, postoperative lung infection, urinary tract infection and incision infection between the two groups. However, the included studies did not analyze the effect of gender. Given the gender difference in senile osteoporosis, gender may also be one of the factors affecting the two surgical approaches. Therefore, gender should be analyzed as an independent factor in subsequent clinical studies. The studies included in this meta-analysis had high quality, but due to the limitation of sample size, a larger sample size and higher quality RCTs should be used for further demonstration.

In conclusion, compared with the uncemented group, the cemented group had an extended operation time and a high incidence of pulmonary embolism, but had an advantage in reducing the prosthesis fracture around the intraoperative and postoperative and short length of hospital stay and had no increased rate of mortality, lower extremity deep vein thrombosis, joint dislocation rate, intraoperative blood loss and postoperative incidence of lung, urinary tract and incision.

\section{Acknowledgements}

We thank Dr An Yang (The Second People's Hospital of Hefei) for the assistance in contributing to the literature search process.

\section{Funding}

The present meta-analysis was funded by Beijing Bethune Medical Scientific Research Fund (N054EN). 


\section{Availability of data and materials}

All data generated or analyzed during this study are included in this published article.

\section{Authors' contributions}

XK designed the study, collected the data and analyzed the data. $\mathrm{XK}$ prepared the manuscript and approved the final manuscript.

\section{Ethics approval and consent to participate}

Not applicable.

\section{Patient consent for publication}

Not applicable.

\section{Competing interests}

The authors declare that they have no competing interests.

\section{References}

1. Collin PG, D'Antoni AV, Loukas M, Oskouian RJ and Tubbs RS Hip fractures in the elderly-: A clinical anatomy review. Clin Anat 30: 89-97, 2017.

2. LeBlanc KE, Muncie HL Jr and LeBlanc LL: Hip fracture: Diagnosis, treatment, and secondary prevention. Am Fam Physician 89: 945-951, 2014.

3. Leal J, Gray AM, Prieto-Alhambra D, Arden NK, Cooper C, Javaid MK and Judge A; REFReSH study group: Impact of hip fracture on hospital care costs: A population-based study. Osteoporos Int 27: 549-558, 2016.

4. Florschutz AV, Langford JR, Haidukewych GJ and Koval KJ: Femoral neck fractures: Current management. J Orthop Trauma 29: 121-129, 2015.

5. Caldwell L, Chan CM, Sanders JO and Gorczyca JT: Detection of femoral neck fractures in pediatric patients with femoral shaft fractures. J Pediatr Orthop 37: e164-e167, 2017.

6. Slobogean GP, Stockton DJ, Zeng BF, Wang D, Ma B and Pollak AN: Femoral neck shortening in adult patients under the age of 55 years is associated with worse functional outcomes: Analysis of the prospective multi-center study of hip fracture outcomes in China (SHOC). Injury 48: 1837-1842, 2017.

7. Jadad AR, Moore RA, Carroll D, Jenkinson C, Reynolds DJ, Gavaghan DJ and McQuay HJ: Assessing the quality of reports of randomized clinical trials: Is blinding necessary? Control Clin Trials 17: 1-12, 1996.

8. Ma C, Jiang F, Huang C and Liu Z: Contrast of effect and prognosis of artificial hip joint maken by biomaterials and bone-cement for femoral neck fracture. Jianyan Yixue Yu Linchuang 13: 1826-1828, 2016.

9. Deangelis JP, Ademi A, Staff I and Lewis CG: Cemented versus uncemented hemiarthroplasty for displaced femoral neck fractures: A prospective randomized trial with early follow-up. J Orthop Trauma 26: 135-140, 2012.

10. Emery RJ, Broughton NS, Desai K, Bulstrode CJ and Thomas TL: Bipolar hemiarthroplasty for subcapital fracture of the femoral neck. A prospective randomised trial of cemented Thompson and uncemented Moore stems. J Bone Joint Surg Br 73: 322-324, 1991.
11. Figved W, Opland V, Frihagen F, Jervidalo T, Madsen JE and Nordsletten L: Cemented versus uncemented hemiarthroplasty for displaced femoral neck fractures. Clin Orthop Relat Res 467: 2426-2435, 2009

12. Inngul C, Blomfeldt R, Ponzer S and Enocson A: Cemented versus uncemented arthroplasty in patients with a displaced fracture of the femoral neck: A randomised controlled trial. Bone Joint J 97-B: 1475-1480, 2015.

13. Li J: Comparison of the effects and complications of biotype and cement-based artificial hip prosthesis in the treatment of femoral neck fracture in the elderly. Clin Med Chin 33: 1127-1130, 2017 (In Chinese).

14. Khorami M, Arti H and Aghdam AA: Cemented versus uncemented hemiarthroplasty in patients with displaced femoral neck fractures. Pak J Med Sci 32: 44-48, 2016.

15. Langslet E, Frihagen F, Opland V, Madsen JE, Nordsletten L and Figved W: Cemented versus uncemented hemiarthroplasty for displaced femoral neck fractures: 5-year followup of a randomized trial. Clin Orthop Relat Res 472: 1291-1299, 2014.

16. Moerman S, Mathijssen NMC, Niesten DD, Riedijk R, Rijnberg WJ, Koëter S, Kremers van de Hei K, Tuinebreijer WE, Molenaar TL, Nelissen RGHH and Vochteloo AJH: More complications in uncemented compared to cemented hemiarthroplasty for displaced femoral neck fractures: A randomized controlled trial of 201 patients, with one year follow-up. BMC Musculoskelet Disord 18: 169, 2017.

17. Parker MI, Pryor G and Gurusamy K: Cemented versus uncemented hemiarthroplasty for intracapsular hip fractures: A randomised controlled trial in 400 patients. J Bone Joint Surg Br 92: 116-122, 2010.

18. Pan S: Comparison of the effects of cemented and uncemented hemiarthroplasty in the treatment of displaced femoral neck fractures. Chin J Postgrad Med 36: 41-43, 2013.

19. Sonne-Holm S, Dyrbye M, Walter S and Jensen JS: Bone scintigraphy in Moore hemiarthroplasty with and without cement following femoral neck fractures. A controlled study. Acta Orthop Scand 54: 194-197, 1983.

20. Talsnes O, Hjelmstedt F, Pripp AH, Reikerås O and Dahl OE: No difference in mortality between cemented and uncemented hemiprosthesis for elderly patients with cervical hip fracture. A prospective randomized study on 334 patients over 75 years. Arch Orthop Trauma Surg 133: 805-809, 2013.

21. Taylor F, Wright M and Zhu M: Hemiarthroplasty of the hip with and without cement: A randomized clinical trial. J Bone Joint Surg Am 94: 577-583, 2012.

22. Vidović D, Punda M, Daraboš N, Bekavac-Bešlin M, Bakota B and Matejčić A: Regional bone loss following femoral neck fracture: A comparison between cemented and cementless hemiarthroplasty. Injury 46 (Suppl 6): S52-S56, 2015.

23. Du Z: Analysis of the effect of cemented and uncemented artificial double femoral head replacement. Chin Med Eng, 29-30, 2014.

24. Sprague S, Slobogean GP, Scott T, Chahal M and Bhandari M: Young femoral neck fractures: Are we measuring outcomes that matter? Injury 46: 507-514, 2015.

25. Grosso MG, Danoff JR, Padgett DE, Iorio R and Macaulay WB: The cemented unipolar prosthesis for the management of displaced femoral neck fractures in the dependent osteopenic elderly. J Arthroplasty 31: 1040-1046, 2016.

26. Azegami S, Gurusamy KS and Parker MJ: Cemented versus uncemented hemiarthroplasty for hip fractures: A systematic review of randomised controlled trials. Hip Int 21: 509-517, 2011.

27. Borghi B, Casati A and Rizzoli Study Group on Orthopaedic Ananesthesia: Thromboembolic complications after total hip replacement. Int Orthop 26: 44-47, 2002.

(i) (-) $\ominus$ This work is licensed under a Creative Commons Attribution-NonCommercial-NoDerivatives 4.0 International (CC BY-NC-ND 4.0) License. 